\title{
STUDIES OF PROTEIN METABOLISM IN INTESTINAL EPITHELIAL CELLS*
}

\author{
By MARTIN LIPKIN AND HENRY QUASTLER \\ (From the Department of Medicine, Cornell University Medical College, Second (Cornell) \\ Medical Division, Bellevue Hospital, and the Biology Department, Brookhaven \\ National Laboratories, Upton, N. Y.)
}

(Submitted for publication September 5, 1961 ; accepted November 16, 1961)

Some aspects of intracellular protein metabolism can be studied with radioactive amino acids. Most previous studies of intestinal cells have involved measurements of incorporation of amino acids into fractions of the entire mucosa (1) and have provided composite measurements of protein synthesis in the tissues. The gastrointestinal mucosa contains numerous connective tissue elements, blood cells, smooth muscle and nerve cells, and several kinds of epithelial cells. In the small bowel the epithelial cells are of four types : Paneth, argentaffine, principal, and goblet cells; the principal cells themselves include proliferating, and differentiating or mature cells. All of these elements synthesize protein, but they synthesize different kinds of protein at different rates. It is desirable to define amino acid incorporation and protein synthesis with respect to particular tissue elements. This can be done by autoradiographic methods. The feasibility and value of this approach have been demonstrated by Leblond, Everett and Simmons (2), using radioactive methionine. In the present study leucine has been used, labeled with tritium for autoradiographic studies, and with $\mathrm{C}^{14}$ for concomitant radiochemical analyses. The kinetics of incorporation, the differences in rate of uptake between cells as well as within cells, and the further fate of incorporated leucine have been studied in some detail. Normal mice were used, as well as mice subjected to protein starvation and to steroid treatment.

\section{METHODS}

Adult male C57 Brown mice were maintained on a standard nutritional diet (3).

* This work was aided by grants from The John A. Hartford Foundation, Inc., the National Cancer Institute (research grant C-3697), the G. D. Searle Co., and the Upjohn Co. Part of the work was performed at the Brookhaven National Laboratories under the auspices of The U. S. Atomic Energy Commission.
For radiochemical studies, $5 \mu \mathrm{c}$ of uniformly labeled $\mathrm{C}^{14}$-leucine specific activity (SA) $8 \mathrm{C} / \mathrm{M}$ ] was injected intraperitoneally in $1 \mathrm{ml}$ of saline. At varying time intervals the animals were sacrificed and various organs removed. The protein fraction was prepared by homogenizing the tissues in 9 vol of cold 5 per cent trichloroacetic acid, then centrifuging and repeating the procedure three times. The residues were then washed successively three times with acetone and three times with ether (4). The protein powder was dried, hydrolyzed, and plated on filter paper in stainless steel planchets. The radioactivity of the incorporated label was counted in a windowless gas-flow counter, infinite thickness corrections made, and specific activity plotted against time.

For autoradiographic studies, animals were injected with $100 \mu \mathrm{c}$ of $\mathrm{H}^{3}$-leucine (SA $370 \mathrm{C} / \mathrm{M}$ ). The mice were killed at various intervals after injection and microautoradiographic studies were done on pieces of jejunum and colon, fixed in neutral formalin, embedded in paraffin, and sectioned at $5 \mu$. Slides carrying sections were dipped into liquid emulsion (NTB), exposed for 2 weeks at $4^{\circ} \mathrm{C}$, developed, stained, and examined. Since the electrons produced in the decay of tritium have a range in tissue of about $1 \mu$, activated silver grains tend to be closely apposed to the structure labeled. It was therefore possible to identify sites of incorporation of tritiated leucine with a resolution of fraction of a cell size. Chromatographic analysis of injected material revealed no free label. In addition, tissues of animals injected were washed with solutions containing trichloroacetic acid. Examination of serial sections before and after washings revealed no change in grain counts. After the washing procedures ninhydrin colorimetric analyses also revealed that no free amino acid was present. This indicated that radioactivity in the tissues was due to tritium incorporated into protein molecules and possibly into some higher polypeptides.

Quantitative estimates of relative rates of leucine incorporation were based on counts of grain density. Since all sections were virtually infinitely thick compared with the range of tritium $\beta$-rays, these counts are proportional to the amount of tritium incorporated. Also, since fading is a minor factor under the conditions used, grain counts are approximately proportional to exposure time and differences in exposure time can be corrected accordingly. One unit (U) of grain density was defined as the number of grains per $64 \mu^{2}$ area per week of exposure per $100 \mu \mathrm{c}$ injected. 


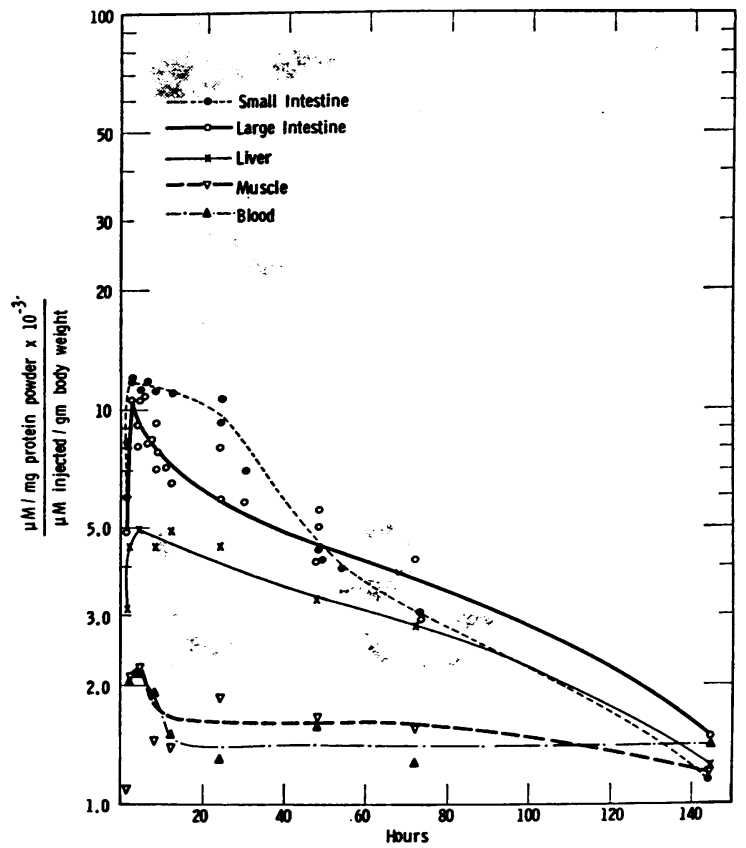

Fig. 1. SPECIFIC ACtivity of $C^{14}$-LEUCINe INCORPORATED INTO PROTEIN PRECIPITATE OF MUCOSA OF SMALL INTESTINE AND OTHER TISSUES. Small intestine has the highest specific activity as well as the most rapid rate of removal of leucine label.

\section{RESULTS}

\section{Chemical studies}

Figure 1 shows the specific activities of leucine incorporated into protein precipitate of mucosa of small intestine and other tissues. The rising portions of the curves indicate the net rate of incorporation of leucine into the proteins of the various tissues; the declining portions indicate the net rate of removal of the label.

Maximum specific radioactivity among the tissues tested was found in small intestine, followed in order by large intestine, liver, muscle, and whole blood. The specific activity curves for the small intestine revealed rapid incorporation of leucine into protein, with the maximum incorporation being found 3 to 4 hours after injection. The declining portions of the specific activity curves began at 6 hours. The label was removed from small intestine with a turnover time of 50 to 60 hours, which is more rapid than in other tissues. These results are similar to the findings of others who used similar extraction procedure (1). In the colon the absolute activities were lower, but the changes with time were similar to those in the small intestine.

\section{Micro-autoradiographic studies}

1. Normal jejunum. Appearance of label: Figure 2 shows a micro-autoradiograph of a jejunal crypt and villus after injection of leucine. Grain counts on micro-autoradiography were highest about 2 to 4 hours after injection. This corresponded to the maximum height of the specific activity curves in the radiochemical studies.

Differential rates of uptake were estimated on the basis of grain density determinations over various histologically defined regions. In the crypts of the jejunum separate grain density estimations were made over Paneth cell nuclei, Paneth cell cytoplasm, principal cell nuclei, and cytoplasm. On the villi, counts were made over villus epithelial cell nuclei, proximal cytoplasm (that half of the cytoplasmic area which is adjacent to the nuclei and basal membrane), and distal cytoplasm (that half adjacent to the cell border). Grain densities were measured separately over epithelial cells at the base, middle, and tip of the villi. Connective tissue in the villus and in the submucosa were similarly studied.

The columnar epithelial cells in the crypts were more heavily labeled than those on the villi, and the villus cells near the base more heavily than those near the tip. Differences in grain densities between cells constitute an intercellular gradient; it is shown in Table I, A.

The grain density within the epithelial cells also varies, which constitutes an intracellular gradient (Table I, B). In the crypts, nuclei

TABLE I

Grain densities at 1.7 hours *

\begin{tabular}{|c|c|c|c|}
\hline \multicolumn{4}{|c|}{ A. Intercellular gradient (nuclei of epithelial cells only) } \\
\hline \multicolumn{4}{|c|}{ Area } \\
\hline Crypt & $8.5 \pm 1.3$ & & \\
\hline Villus base & $4.2 \pm 1.2$ & & \\
\hline middle & $3.2 \pm 0.7$ & & \\
\hline tip & $2.6 \pm 0.6$ & & \\
\hline \multicolumn{4}{|c|}{ B. Intracellular gradient (villi only) } \\
\hline Epithelial cells & Villus base & Villus middle & Villus tip \\
\hline Distal cytoplasm & $6.1 \pm 1.4$ & $6.1 \pm 1.2$ & $4.4 \pm 1.2$ \\
\hline Proximal cytoplasm & $4.6 \pm 0.9$ & $4.3 \pm 0.8$ & $2.9 \pm 0.5$ \\
\hline Nucleus & $4.2 \pm 1.2$ & $3.2 \pm 0.7$ & $2.6 \pm 0.6$ \\
\hline Connective tissue & $3.4 \pm 1.2$ & $2.6 \pm 0.5$ & $2.1 \pm 0.5$ \\
\hline
\end{tabular}

* Grains per $64 \mu^{2}$ per $100 \mu c$ per 1 week exposure and standard deviations over epithelial cells and between crypts and villi. 

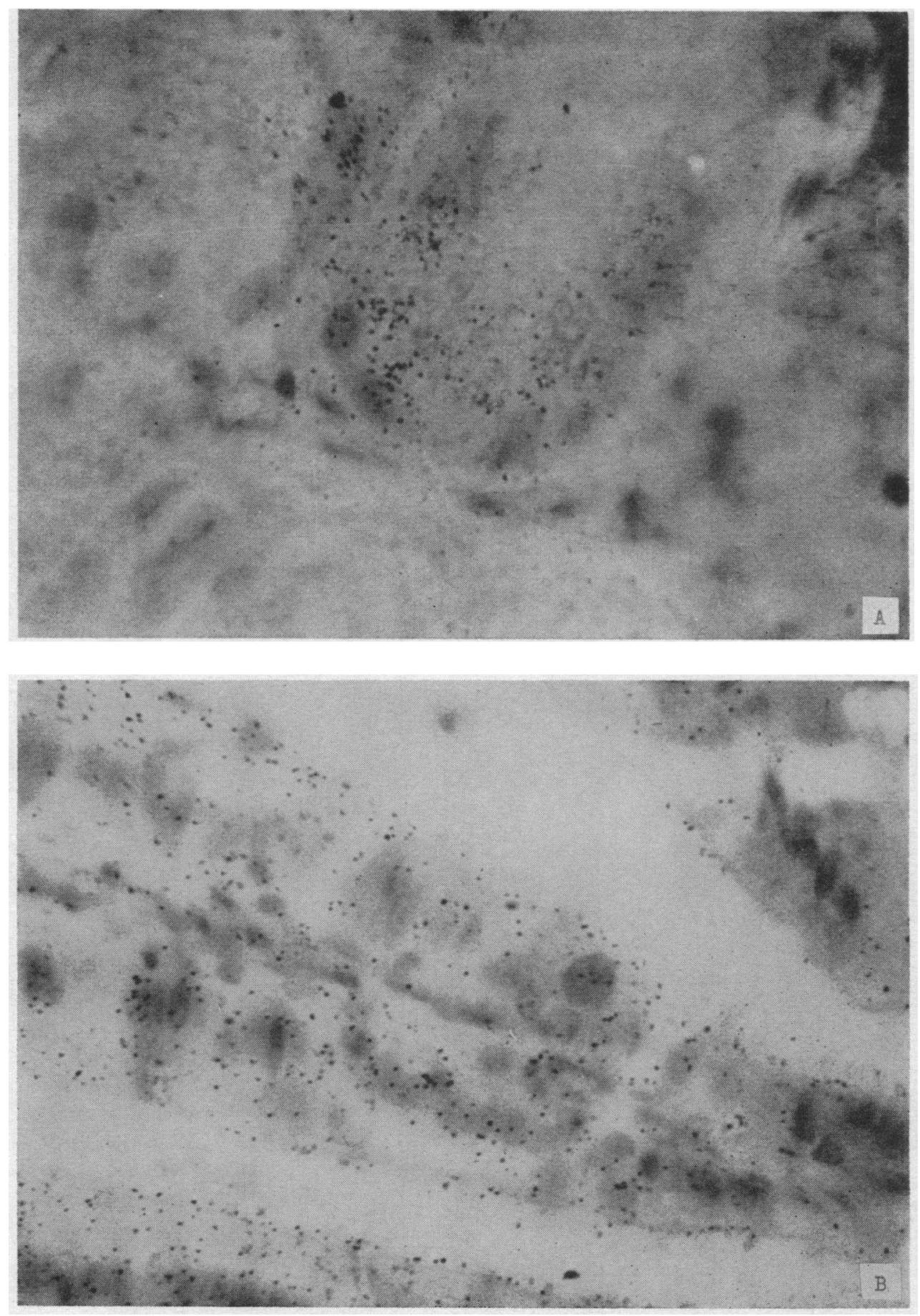

Fig. 2. A. Micro-Autoradiograph of Jejunal CRypt 1 hour after injection of H $^{3}$-leucINE. Leucine grains are seen over cytoplasm and nuclei of crypt epithelial cells, as well as over Paneth cells. Very little label is seen over submucosa. B. Micro-Autoradiograph or JEJUNAL VILLUS 1 hOUR AFTER INJECTION OF $\mathrm{H}^{3}$-LEUCINE. Leucine grains are present over cytoplasm and nuclei of villus epithelial cells. Less label is seen over connective tissue elements in lamina propria. 


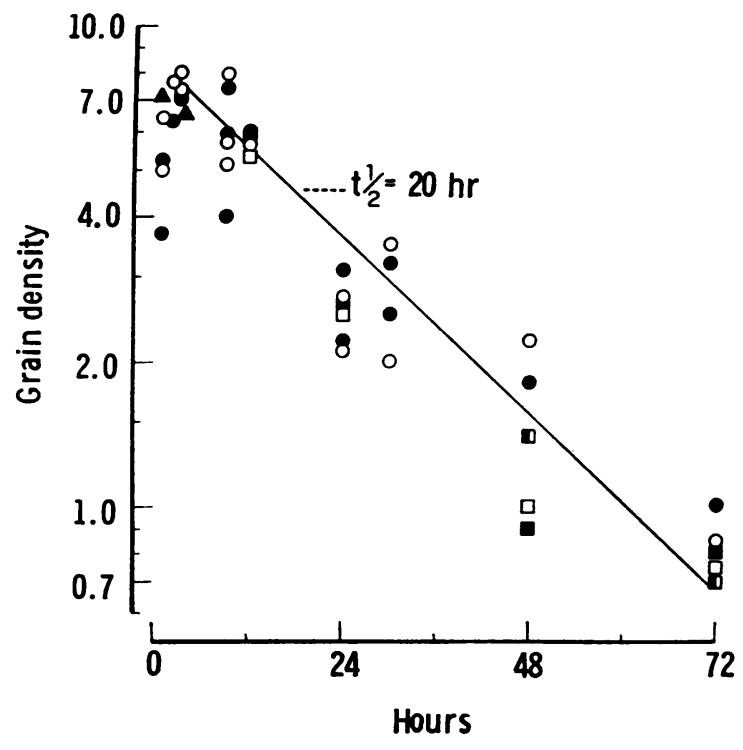

Fig. 3. Grain densities (GRains Per $64 \mu^{2}$ Per $100 \mu \mathrm{C}$ PER WEEK EXPOSURE) OVER JEJUNAL CRYPT EPITHELIAL CELlS, PLOTTEd AGAINST TIME. Each point represents one animal. The circles and other symbols indicate separate experiments. Empty symbols, cytoplasm; full symbols, nuclei.

and cytoplasm were about equally labeled 2 to 4 hours after injection. On the villi, nuclei were less heavily labeled than cytoplasm. The "nuclear" counts here given include some surrounding cytoplasm, and measurement of nuclei that were cut straight through the center revealed lower counts than are recorded here. The grain count over the distal cytoplasm was higher than over the proximal, with a considerable fraction of the grains deposited near the surface. This was much more pronounced in villus cells than in crypt cells. This finding was not an artifact. Other free surfaces on the same slides did not show this effect. In some instances villi were split during sectioning, and the inner free surfaces also did not show heavy grain counts. In addition, after administration of $\mathrm{H}^{3}$-cytidine, grain counts were of the same order as those seen with leucine. Much label was seen in the cytoplasm, but not near the surface, the distribution being quite different from that seen after leucine injection. It is concluded that the concentration of label near the surface is indicative of a high rate of protein synthesis in this region; this is compatible with the rapid growth of microvilli (5) and with histochemical demonstration of enzyme concentration in and adjacent to the microvilli (6).

Disappearance of label: The heavy clusters of grains over the Paneth cells disappeared rapidly, and grains appeared over the lumen of the crypts. Over other structures the changes were less rapid. Studies of micro-autoradiographs of animals sacrificed up to 3 days after labeling yielded the data shown in Figures 3-5. In the crypts (Figure 3) the grain density reached a peak of about $7.5 \mathrm{U}$ shortly after labeling, and then declined roughly exponentially with a half-life of about 20 hours. A decline of grain density at this rate should result if there is no intracellular degradation and loss of protein in these proliferating cells. They have been shown to divide approximately every 19 hours (7). At each division the labeled protein is diluted to one-half by production of new unlabeled protein, each daughter cell receiving roughly equal amounts of labeled and unlabeled protein. The data, however, are not precise enough to exclude a minor loss of labeled protein.

The results of counts taken over the base of the villi are shown in Figure 4 . In preparations taken up to 12 hours after labeling, the cytoplasm showed heavier label (about $5.6 \mathrm{U}$ ) than did the nuclei (about 4.2). In preparations taken 1 day later this difference disappeared. The peak grain count, reached between 12 and 24 hours, was near 5.5. The grain count declined roughly exponentially in from 1 to 3 days. These changes,

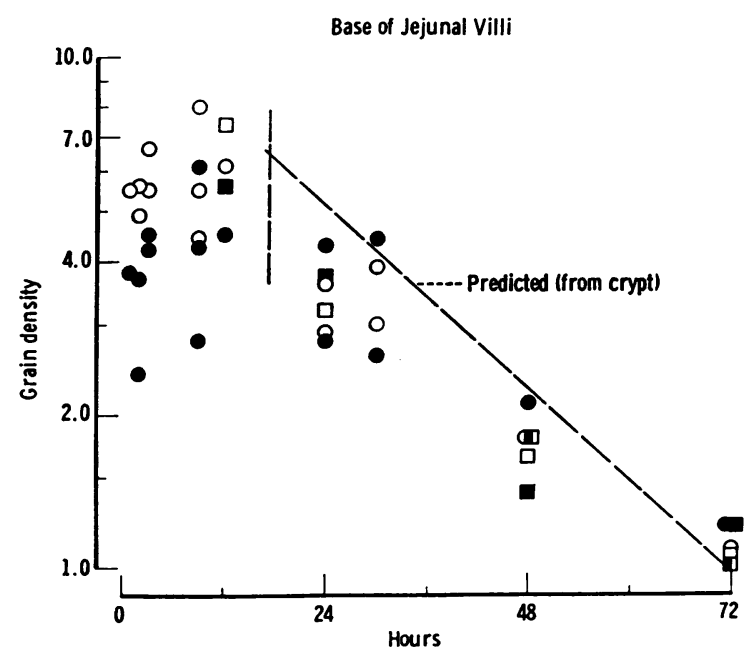

Fig. 4. Grain densities over Jejunal epithelial cells AT BASE OF villus, PLOTTED AGAINST TIME. 


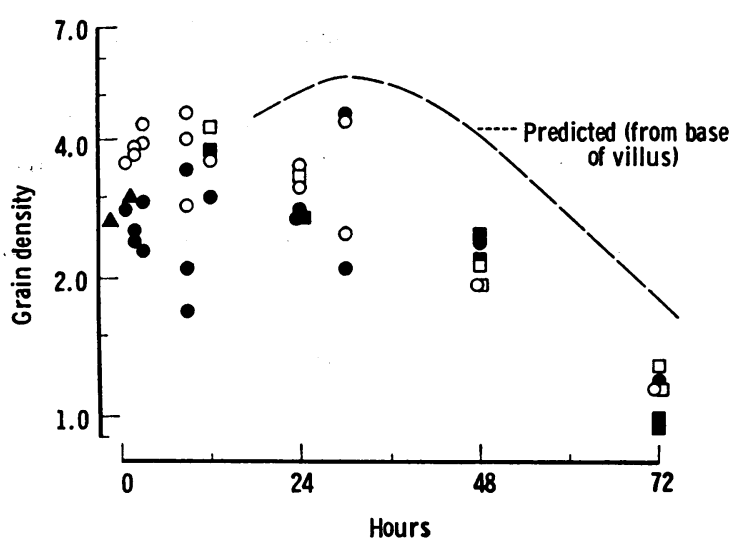

Fig. 5. Grain densities over Jejunal epithelial cells AT TIP OF VILLUS, PLOTTED AGAINST TIME.

again, can be accounted for by movement of cells from the crypts onto the base of the villi, and from the base to the tip.

Within about 1.75 days after labeling, the cells that occupied the base of the villi at the time of injection have been replaced by cells that have come up from the crypts (7). Some of these have divided before leaving the crypts; others, in process of differentiation at the time of labeling, have left without previous division. Hence, the maximum grain count reached at the base of the villi should be replaced by the more equal distribution of label over the crypt cells. For later periods the counts should decline exponentially, with a half-life of about 20 hours. The data shown in Figure 4, while compatible with the hypothesis of migration without loss of protein, are of low precision and would not exclude a loss of up to $1 / 4$ of the label occurring during the $3 / 4$-day migration from the mouth of the crypts to the region near the base of the villi.

The cells that pass through the base of the villi reach the region of the tip 1 day later. If there were no loss of label during this migration the grain counts over the tips of the villi should follow the dashed line in Figure 5. Actually, the values, obtained 30 hours and later after labeling, are about one-half less. This indicates that, during migration, about one-half the label was lost.

2. Normal colon. Grain density determinations were made over the cells in the ascending colon. The epithelial cells were classified by position at the lower, middle, and upper third of the crypts, and at the surface. In each of these five regions nuclei and cytoplasm were evaluated separately. Counts were also made over connective tissue.

At 3 hours the grain density in the lower twothirds of the crypts was about twice that at the surface, with intermediate values in the upper third of the crypt. The cytoplasm was more heavily labeled than were the nuclei-the mean grain density was $13.4 \mathrm{U}$ over the cytoplasm, 9.8 over the nuclei. At 24 hours the labeling over nuclei and cytoplasm was approximately equal, and at 48 and 72 hours the nuclei were more heavily labeled than was the cytoplasm; the $t_{\frac{1}{2}}$ for the nuclei was approximately 38 hours, compared with a $t_{\frac{1}{2}}$ of about 24 hours for the cytoplasm.

3. Effects of protein-free diet. Eight mice were put on a diet containing the same amount of calories as the standard diet but no protein (3). On this diet they began to lose weight and muscle mass immediately and were down to about twothirds of their original weight in 2 weeks. At that time eight animals were injected with $\mathrm{H}^{3}-$ thymidine and killed at 1,12 , and 24 hours, respectively, to check cell proliferation and movement (7). It was found that cell population kinetics were not grossly altered under these conditions. Eight mice were injected with $\mathrm{H}^{3}$ leucine or $\mathrm{C}^{14}$-leucine and killed at various intervals, to study utilization and subsequent loss

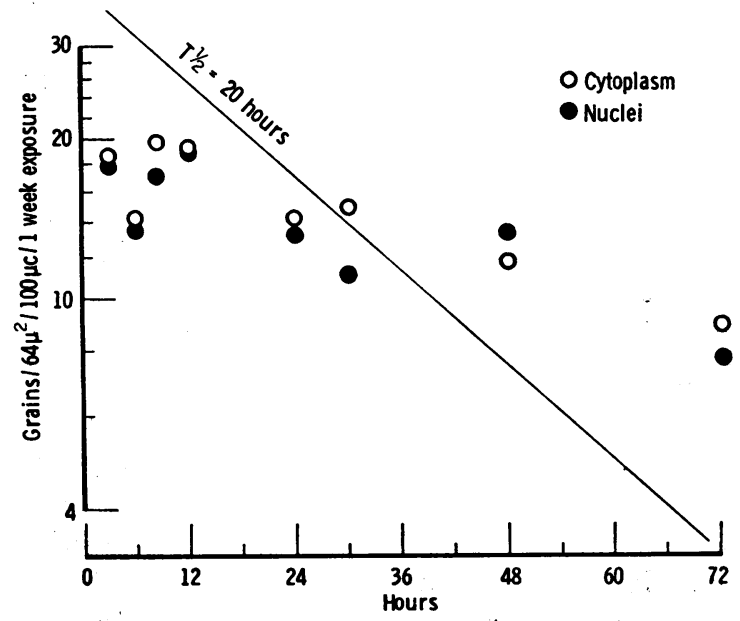

Fig. 6. GRain Densities over Jejunal CRYPT EPITHELIAL CELls, PlotTed AGAINST TIME, AFTER PROTEINFREE DIET. $T_{\frac{1}{2}}$ of 20 hours derived from experiment with normal diet (Figure 3) superimposed. 
of leucine. By both autoradiographic and chemical methods it was found that the original uptake of labeled leucine was about twice normal, and that the subsequent falloff was very much slower than in normal mice (Figure 6). The time course of grain densities over the crypts and villi showed that the net loss of label from the epithelial cells was less than normal. Histologically, the jejunum showed loss of Paneth cell granules but little change in the proliferative cells, although their total number was slightly reduced. The colon, in contrast, was markedly atrophied. After injection with $\mathrm{H}^{3}$ leucine, cells were heavily labeled.

4. Effects of continuous steroid administration. Eight animals were placed on the normal diet and treated with large doses of cortisone, $1.5 \mathrm{mg}$ per mouse per day, equivalent on a weight basis to about $3,000 \mathrm{mg}$ per day given to a human. Cortisone was administered for 17 days, and animals were subsequently studied with $\mathrm{H}^{3}$-leucine and $\mathrm{H}^{3}$-thymidine.

The amount of leucine incorporated was slightly higher than in the normal series, and maximum grain densities in the crypts were cytoplasm, 13 $\mathrm{U}$ and nuclei, $10 \mathrm{U}$. $\mathrm{H}^{3}$-thymidine studies indicated no gross alteration in cell proliferation kinetics. The falloff rate of leucine label in jejunum seemed to be less rapid than in the controls, although more rapid than the falloff rate following starvation. It could be that a slight slowing of cell proliferation occurred, owing to the cortisone, or that the negative nitrogen balance induced by cortisone contributed to reutilization of labeled material here too.

\section{DISCUSSION}

Labeled leucine was used to study the uptake of this amino acid into protein and its subsequent fate. By combining chemical and autoradiographic methods, it was possible to partition the over-all changes in specific activity of protein into contributions due to the various types of cells. Furthermore, by combining the results obtained with labeled protein and labeled DNA, it was possible to correlate the observations on synthesis and loss of protein with proliferation and subsequent differentiation, movement, and decay of cells.

Proliferative cells. The heavy concentration of label in the proliferative cells of the crypts in jejunum and colon indicates rapid protein synthesis in the proliferating cells. With both leucine (8) and methionine (2), the labeling over proliferative cells is much heavier than over mature cells. The disappearance of label from the proliferative zones can be accounted for by emigration of labeled cells and continued protein synthesis from endogenous precursors.

Mature cells. The primary distribution of label over the mature cells of the jejunal villus is correlated with synthetic activity, and the subsequent change can be accounted for by a combination of cell migration and loss of some of the protein.

The findings reported here indicate that protein in the proliferating epithelial cells of the jejunum is either highly stable or, if broken down, is reutilized not only in the same cell but even in the same fraction of the cell. It is proposed that, in the rapidly growing cells of the intestinal epithelium, synthesized protein is sufficiently stable to last through the proliferative cycle of the cells, and intracellular degradation or protein turnover does not have a significant role in fixing the net rate of protein synthesis or in contributing appreciably to the composition and protein structure of the proliferating cells. In the mature cell, studies with labeled leucine yield evidence of a moderate degree of protein loss. Leblond and co-workers (2), following $\mathrm{S}^{35_{-}}$ labeled methionine incorporated into the epithelial cells of the duodenum of the rat, found retention of apparently most of the label during migration of the cells to the tips of the villi; however, these authors give no grain counts. It is not known how much of the protein lost from mature intestinal epithelial cells is accounted for by secretion of intact protein from the cells, or from loss of protein molecules that have undergone intracellular degradation. It may well be that, in the mature cell, protein contained in the vesicular endoplasmic reticulum of the proliferative cell undergoes degradation, and possibly is partly reutilized in forming the tubular endoplasmic reticulum of the mature cells, enzymes, and microvilli. Protein could possibly be degraded to amino acids and quickly reutilized for new protein synthesis at approximately the same intracellular site. However, excessive amounts of endogenous amino acids present in the intestinal lumen would pre- 
clude against random incorporation and resynthesis from the total cell-free pool.

The Paneth cells, at the bottom of the jejunal crypts, are mature cells. They show heavy labeling over the granules and rapid disappearance of label. This behavior agrees with the supposition that these granules contain secretory products (9). It is known that Paneth granules disappear rapidly after meals.

Other secretory cells incidentally observed, such as liver and pancreas, also show clear evidence of protein turnover. In general, then, there seems to be little if any turnover of protein in proliferative cells, contrasted with moderate to rapid turnover in mature cells. These findings do not support the concept (1) of "dynamic equilibrium" of proteins in mammalian cells. They do agree, however, with the results of a number of recent studies on single cells : in log phase bacteria, protein once synthesized is stable $(10,11)$. Similar evidence was found in growing mammalian cells of the L strain in tissue culture (12). In yeast, protein breakdown was found in resting cells but a much smaller rate of degradation obtained in dividing cells (13).

The protein-starved animals show a striking contrast between the approximately normal rate of cell production and, by implication, of protein synthesis in the small bowel, in contrast to the progressive atrophy of the colon and many other organs. It has been shown that protein-starved animals incorporate labeled lysine in intestinal tissues at a higher rate than do normals, a finding that has been thought to indicate a re-direction of protein metabolism in favor of vital enzymes and structures in the intestinal organs (14). In our study the high uptake of labeled leucine into, and histologically normal appearance of small intestine is in agreement with these findings. The appearance of the colon, however, suggests that it does not participate in a re-direction of protein metabolism to the same extent as does the jejunum. The very low rate of leucine falloff in jejunum, as compared with normal animals, illustrates the ability of the intestinal cells to reutilize endogenous amino acid or other protein precursors derived from previously labeled protein, a considerable fraction of which probably was originally synthesized in the intestine.

\section{SUM MARY}

The gastrointestinal mucosa contains several types of epithelial cells and other cellular elements. All cells synthesize protein, but the different cell types synthesize different kinds of protein at different rates. It is desirable to define amino acid incorporation and protein synthesis with respect to particular cell types. In this study leucine was used, labeled with tritium for microautoradiographic studies and with $\mathrm{C}^{\mathbf{1 4}}$ for concomitant radiochemical analyses. The kinetics of incorporation, the differences in rate of uptake between cells as well as within cells, and the further fate of incorporated leucine were studied. By combining the results obtained with labeled protein and labeled DNA, it was possible to correlate the observations on synthesis and loss of protein with proliferation and subsequent differentiation, movement, and decay of cells.

The results revealed greater incorporation of leucine into rapidly proliferating epithelial cells located in the jejunal crypts, compared with villus epithelial cells, shortly after injection of $\mathrm{H}^{3}$-leucine. Grain densities within the epithelial cells also varied. In villus epithelial cells nuclei were less heavily labeled than was cytoplasm, and cytoplasm adjacent to nuclei was less heavily labeled than cytoplasm adjacent to microvilli. Paneth cells showed heavy labeling over the granules after injection of $\mathrm{H}^{3}$-leucine, and rapid disappearance of label.

The findings also revealed a high degree of stability of synthesized protein in rapidly proliferating crypt epithelial cells, and a slow loss of protein from mature cells during their migration to the villus tip. When mice were placed on a diet containing the same amount of calories but no protein, the colon and other tissues atrophied markedly, but the jejunum did not. In the jejunum the rate of cell proliferation was approximately normal. The rate of removal of leucine, however, was greatly reduced, indicating reutilization of endogenous amino acid or of other protein precursors derived from previously labeled protein.

\section{ACKNOWLEDGMENTS}

We gratefully acknowledge the advice and assistance of Dr. Thomas P. Almy, and the technical assistance of Mrs. Helen Fuss and Miss Agnes Smith. 


\section{REFERENCES}

1. Schoenheimer, R. The Dynamic State of Body Constituents. Cambridge, Mass., Harvard Univ. Press, 1942.

2. Leblond, C. P., Everett, N. B., and Simmons, B. Sites of protein synthesis as shown by radioautography after administration of $\mathrm{S}^{35}$-labelled methionine. Amer. J. Anat. 1957, 101, 225.

3. Brush, M. K., McCoy, J. R., Rosenthal, H. L., Stauber, L. A., and Allison, J. B. The addition of non-ionic surface-active agents of the polyoxyethylene type to the diet of the hamster, the mouse and the dog. J. Nutr. 1957, 62, 601.

4. Lajtha, A., Furst, S., Gerstein, A., and Waelsch, H. Amino acid and protein metabolism of the brain. I. Turnover of free and protein bound lysine in brain and other organs. J. Neurochem. 1957, 1, 289.

5. Palay, S., and Karlin, J. An electron microscopic study of the intestinal villus. I. The fasting animal. J. biophys. biochem. Cytol. 1959, 5, 363.

6. Shnitka, T. K. Enzymatic histochemistry of gastrointestinal mucous membrane. Fed. Proc. 1960, 19, 897.
7. Quastler, H., and Sherman, F. G. Cell population kinetics in the intestinal epithelium of the mouse. Exp. Cell Res. 1959, 17, 420.

8. Lipkin, M., Almy, T. P., and Quastler, H. Stability of protein in intestinal epithelial cells. Science 1961, 133, 1019.

9. Selzman, H. M., and Liebelt, R. A. A cytochemical analysis of Paneth cell secretion in the mouse. Anat. Rec. 1961, 140, 17.

10. Hogness, D. S., Cohn, M., and Monod, J. Studies on the induced synthesis of B-galactosidase in Escherichia coli: The kinetics and mechanism of sulfur incorporation. Biochim. biophys. Acta 1955, 16, 99.

11. Rotman, B., and Spiegelman, S. On the origin of carbon in induced synthesis of B-galactosidase in Escherichia coli. J. Bacteriol. 1954, 68, 419.

12. King, D. W., Bensch, K. G., and Hill, R. B., Jr. State of dynamic equilibrium in protein of mammalian cells. Science 1960, 131, 106.

13. Halvorson, $H$. Intracellular protein and nucleic acid turnover in resting yeast cells. Biochim. biophys. Acta 1958, 27, 255.

14. Schreier, K., and Kazassis, C. Influence of different types of malnutrition on the ${ }^{14} \mathrm{C}$-lysine metabolism in young rats. Nature (Lond.) 1960, 187, 1117. 